\title{
The effect of drug information service using leaflet media and medication reminder chart on adherence and blood pressure of hypertensive patients in primary health care
}

\section{Pengaruh PIO menggunakan media leaflet dan medication reminder chart terhadap kepatuhan dan tekanan darah pasien hipertensi di fasilitas pelayanan kesehatan primer}

\author{
Yopi Rikmasari* \\ Program Studi S1 Farmasi, STIFI Bhakti Pertiwi, Palembang, Indonesia \\ *Corresponding author: mpie030178@gmail.com
}

\begin{abstract}
Background: Treatment adherence is an important factor affecting blood pressure control in hypertensive patients. Intervention in pharmacy service can improve medication adherence and lower blood pressure.

Objective: This study aimed to evaluate the effect of drug information service using leaflet and MRC on the level of patient compliance and lowering blood pressure.

Method: The research design was a quasi-experimental pre- and post-design with control, the intervention group $(n=20)$ and the control group $(n=20)$. The patient adherence was measured using the MGLS questionnaire at the beginning and the end of the study. The intervention performed by distribution drug information leaflet and medication reminder chart (MRC). The differences of adherence pre and post intervention were analyzed using paired t-test, while the differences of adherence and blood pressure between the control and the intervention group were analyzed using the Mann-Whitney test.

Results: The results showed that there was a significant difference of adherence between pre and post intervention $(p<0.001)$. A significant difference also found in the level of adherence between the control group and the intervention group $(p<0.001)$. Whereas the decrease of systolic $(p=0.396)$ and diastolic $(p=0.564)$ blood pressure in intervention group and control group was not different significantly.

Conclusion: Drug information services using leaflet and MRCs affected patient adherence medication, but did not interfere the decrease of systolic and diastolic blood pressure.

Keywords: leaflets, medication reminder chart, adherence, blood pressure

\section{Intisari}

Latar belakang: Kepatuhan pengobatan merupakan faktor penting yang mempengaruhi pengendalian tekanan darah pada pasien hipertensi. Intervensi dalam pelayanan kefarmasian diketahui dapat meningkatkan kepatuhan pengobatan dan menurunkan tekanan darah.

Tujuan: Penelitian ini bertujuan untuk mengetahui pengaruh PIO (PIO) menggunakan media leaflet disertai pemberian MRC terhadap tingkat kepatuhan pasien dan penurunan tekanan darah.

Metode: Desain penelitian berupa quasi-experimental dengan pre-test dan post-test design with control group. Subjek penelitian pada tiap kelompok intervensi $(n=20)$ dan kelompok kontrol $(n=20)$. Kepatuhan pasien diukur menggunakan kuesioner MGLS pada awal penelitian dan empat minggu setelah intervensi. Uji-t berpasangan digunakan untuk menganalisis perbedaan kepatuhan sebelum dan sesudah intervensi, sedangkan perbedaan kepatuhan dan perubahan tekanan darah antara kelompok intervensi dan kontrol dianalisis dengan uji mann-whitney.

Hasil: Hasil penelitian memperlihatkan ada perbedaan kepatuhan yang signifikan antara sebelum dan sesudah mendapatkan intervensi $(\mathrm{p}<0,001)$. Selain itu, tingkat kepatuhan minum obat antara kelompok kontrol dan kelompok intervensi juga berbeda signifikan $(\mathrm{p}<0,001)$, sedangkan penurunan tekanan darah sistolik $(\mathrm{p}=0,396)$ dan tekanan darah diastolik $(\mathrm{p}=0,564)$ pada kelompok intervensi dan kelompok kontrol tidak terdapat perbedaan yang signifikan.
\end{abstract}


Kesimpulan: PIO menggunakan media leaflet disertai pemberian MRC mempengaruhi tingkat kepatuhan minum obat pasien, namun tidak memberikan pengaruh terhadap penurunan tekanan darah sistolik dan diastolik.

Kata kunci: leaflet, medication reminder chart, kepatuhan, tekanan darah

\section{Pendahuluan}

Prevalensi hipertensi di Indonesia secara nasional terus mengalami kenaikan. Data riset kesehatan dasar memperlihatkan prevalensi hipertensi berdasarkan diagnosis dokter pada tahun 2007 sebanyak 7,2\% bertambah menjadi 8,36 \% pada tahun 2018 (Kemenkes, 2019a), sedangkan berdasarkan pengukuran tekanan darah sebesar 25,8\% pada tahun 2013 menjadi 34,11\% tahun 2018. Prevalensi hipertensi di Provinsi Sumatera Selatan, yaitu 30,44 \%, sedikit lebih rendah dibandingkan dengan angka nasional (Badan Penelitian dan Pengembangan Kesehatan, 2019).

Penyakit kardiovaskular, serebrovaskular dan penyakit ginjal teridentifikasi disebabkan karena tekanan darah tidak terkontrol (Dipiro et al., 2017). Faktor yang mempengaruhi terkontrolnya tekanan darah sangat kompleks, suatu review melaporkan faktor individu yaitu jenis kelamin, ras/etnik, kepatuhan dan faktor sistem yaitu ketersediaan tempat berobat dan inersia terapi merupakan faktor yang mempengaruhi terkontrolnya tekanan darah (Carey et al., 2018). World Health Organization mendefinisikan kepatuhan tidak hanya terbatas pada kebiasaan pasien dalam minum obat, namun termasuk melakukan perubahan gaya hidup sesuai dengan anjuran yang diberikan oleh penyediaan layanan kesehatan (WHO, 2003). Kepatuhan minum obat merupakan perilaku pasien yang menggunakan obat secara terus-menerus atau rutin sesuai rekomendasi dokter (Ho et al., 2009).

Proporsi kepatuhan penduduk dewasa usia $\geq 18$ tahun dalam minum obat antihipertensi di Provinsi Sumatera Selatan yaitu rutin minum obat $52,4 \%$, tidak rutin minum obat $33,2 \%$, dan tidak minum obat $14,3 \%$. Pasien tidak minum obat secara rutin karena beberapa alasan yaitu sudah merasa sehat (54,30\%), tidak rutin berobat (43,77\%), minum obat tradisional $(21,41 \%)$, sering lupa $(19,27 \%)$, tidak mampu beli obat rutin $(13,74 \%)$, tidak nyaman terhadap efek samping obat (7,87\%), obat tidak tersedia (1,2\%) dan alasan lainnya (7,05\%) (Kemenkes, 2019b).

Pada saat diketahui tingkat kepatuhan pasien hipertensi buruk, maka perlu dilakukan intervensi untuk meningkatkan dan mempertahankan kepatuhan dalam jangka waktu yang panjang (Burnier \& Egan, 2019). Peningkatan kontrol tekanan darah, kepatuhan minum obat antihipertensi, dan pencegahan penyakit kardiovaskuler dapat dilakukan dengan pemberian intervensi dalam bentuk satu atau kombinasi dari beberapa aktivitas, seperti manajemen pengobatan, pemberian edukasi tentang penyakit hipertensi dan gaya hidup, konseling kepatuhan obat, serta pemberian pengingat minum obat. Selain itu, juga dapat dilakukan perbaikan sistem administrasi, kontak pasien 
secara personal, pengukuran tekanan darah secara rutin, atau pelatihan tenaga kesehatan (Omboni \& Caserini, 2018).

Pelayanan farmasi klinis pada pasien hipertensi dapat dilakukan melalui pengkajian dan pelayanan resep, PIO, konseling, dan pemantauan terapi obat (PTO) (Kemenkes, 2019c). Pemberian informasi obat kepada pasien berpengaruh secara signifikan terhadap kepatuhan pasien hipertensi ( $\mathrm{p}=0,040)$ di Puskesmas Umbulharjo I Yogyakarta. Penelitian lainnya melaporkan terdapat pengaruh yang signifikan PIO terhadap kepatuhan $(\mathrm{p}=0,002)$ dan penurunan tekanan darah $(\mathrm{p}<0,001)$ pada pasien PROLANIS (Program Pengelolaan Penyakit Kronis) hipertensi (Idacahyati, 2018). Penelitian sebelumnya melaporkan bahwa pill box terbukti memperbaiki kepatuhan $(\mathrm{p}<0,001)$ serta menurunkan tekanan darah systolic $(\mathrm{p}<0,001)$ dan diastolic $(\mathrm{p}=0,002)$ dengan signifikan, sedangkan pemberian kartu pengingat pengobatan hanya efektif terhadap peningkatan kepatuhan $(\mathrm{p}<0,001)$. Uji coba kombinasi intervensi pelayanan kefarmasian perlu dilakukan untuk meningkatkan kepatuhan minum obat dan mencapai pengendalian tekanan darah pada pasien hipertensi (Sammulia et al., 2016).

Pada penelitian ini akan dikombinasikan intervensi dengan edukasi melalui PIO menggunakan media leaflet, memberikan pengingat minum obat menggunakan MRC dilakukan kontak secara personal oleh mahasiswa farmasi yang telah mendapatkan pelatihan sebelumnya kemudian menganalisis pengaruhnya terhadap kepatuhan dan penurunan tekanan darah pada pasien hipertensi di fasilitas pelayanan kesehatan primer.

\section{Metode}

\subsection{Teknik pengumpulan sampel}

Penelitian ini dilakukan pada periode waktu bulan April sampai Mei 2021 di Puskesmas Abab, Kabupaten Penukal Abab Lematang Ilir Provinsi Sumatera Selatan dengan kriteria subjek yaitu pasien dengan diagnosa hipertensi tanpa komplikasi usia $\geq 18$ tahun, minimal 3 kali kontrol ke puskesmas, dan belum pernah mendapatkan PIO secara kontak personal serta MRC. Teknik pengambilan sampel menggunakan metode kuota sampling. Jumlah sampel tiap kelompok intervensi dan kontrol pada penelitian eksperimen sederhana adalah antara 10 sampai 20 orang (Sugiyono, 2019). Oleh karena itu, jumlah sampel pada penelitian ini ditetapkan sebanyak 40 orang yang dibagi 2 kelompok, yaitu kelompok kontrol 20 orang dan kelompok intervensi 20 orang. Penelitian ini telah disetujui oleh Komite Etik Penelitian Kesehatan Politeknik Kesehatan Kemenkes Palembang dengan Nomor 1226/KEPK/adm2/VI/2021. 


\subsection{Rancangan penelitian}

Penelitian ini dilaksanakan dengan rancangan quasi experimental pre and post design with control. Data dikumpulkan secara prospektif berupa kepatuhan minum obat dan outcome klinis-yang dinilai dari tekanan darah pada subjek penelitian. Pengukuran kepatuhan dan tekanan darah diukur pada awal dan akhir penelitian yaitu pada minggu keempat. Penelitian ini merupakan pilot study, sebagai uji coba awal sebelum dilaksanakan pada sampel yang lebih besar. Semua subjek penelitian telah mendapat penjelasan penelitian dan setuju ikut serta dalam penelitian dengan menandatangani informed consent.

\subsection{Instrumen penelitian}

Kepatuhan minum obat dinilai dengan kuesioner MGLS (Morisky Green Levine Adherence Scale), terdiri dari 4 item yang telah diuji validitas dan reliabilitas di Indonesia pada pasien diabetes mellitus. Nilai reliabilitas konsistensi internal cronbach's $\alpha$ yaitu 0,651 dan reliabilitas tes-retes dengan Spearmans rank correlation sebesar 0,425 serta validitas konvergen dengan nilai $r=0,58$ (Kristina et al., 2019). Subjek penelitian diminta untuk mengisi kuesioner dengan memilih jawaban "ya" atau "tidak". Responden mendapatkan skor 1 jika menjawab "ya" dan skor 0 jika menjawab "tidak". Hasil penilaian ditotal dan disimpulkan kepatuhan rendah jika subjek penelitian menjawab "ya" untuk 4 item, kepatuhan sedang jika pasien menjawab "ya" untuk 1 - 3 item dan kepatuhan tinggi jika pasien menjawab "ya” untuk 0 item.

\subsection{Bentuk intervensi}

Intervensi dilakukan oleh mahasiswa program studi sarjana farmasi semester akhir yang telah dilatih sebelumnya oleh apoteker akademisi dan mempunyai pengalaman melaksanakan pelayanan kefarmasian di sarana pelayanan kefarmasian. Kedua kelompok mendapatkan perlakuan yang sama seperti biasanya oleh petugas ruang obat di puskemas yaitu mendapatkan informasi mengenai nama obat dan aturan pakai, sedangkan pada kelompok intervensi mendapatkan tambahan PIO menggunakan media leaflet dan pemberian MRC. Leaflet yang digunakan dibuat oleh Kementerian Kesehatan Republik Indonesia agar konten leaflet sudah tervalidasi, sedangkan MRC disesuaikan dengan periode pengambilan obat dari subjek penelitian.

\subsection{Analisis data}

Data karakteristik sosiodemografi, gaya hidup dan penyakit dianalisis secara deskriptif dalam bentuk frekuensi dan persentase. Kelompok intervensi dan kelompok kontrol dibandingkan untuk kesetaraan dalam karakteristik dasar menggunakan Chi-square (sebagai alternatif digunakan uji fisher atau Kruskal-wallis) untuk data kategorik (Still et al., 2020). Uji-t berpasangan digunakan untuk menganalisis perbedaan kepatuhan sebelum dan sesudah intervensi (sebagai alternatif 
digunakan uji mann-whitney). Perbedaan penurunan tekanan darah dan kepatuhan pada kelompok intervensi dan kontrol dianalisis dengan uji-t tidak berpasangan (sebagai alternatif digunakan uji wilcoxon). Proses analisis data menggunakan Software SPSS versi 26.

\section{Hasil dan pembahasan}

Penelitian ini merupakan penelitian pilot study, yang bertujuan menganalisis pengaruh PIO menggunakan media leaflet disertai pemberian MRC terhadap tingkat kepatuhan pasien dan penurunan tekanan darah di fasilitas pelayanan kesehatan primer. Jumlah 40 subjek penelitian dibagi sama rata pada kelompok intervensi dan kelompok kontrol. Data karakteristik dasar antara kelompok intervensi dan kelompok kontrol untuk melihat perbedaan karakteristik diantara kedua kelompok tersebut. Hasil uji menunjukkan tidak terdapat perbedaan karakteristik sosiodemografi, gaya hidup dan penyakit pada kedua kelompok tersebut yang meliputi jenis kelamin, usia, pendidikan, pekerjaan, penghasilan, status, BMI (body mass index), olahraga, lama sakit dan derajat hipertensi dimana diperoleh nilai $p$ value $>0,050$. Data sosiodemografi, gaya hidup dan penyakit tercantum pada Tabel 1.

Tabel 1. Data sosiodemografi, gaya hidup dan penyakit

\begin{tabular}{|c|c|c|c|c|c|c|}
\hline \multicolumn{2}{|c|}{ Variabel } & \multicolumn{2}{|c|}{$\begin{array}{c}\text { Kelompok } \\
\text { intervensi }(n=20)\end{array}$} & \multicolumn{2}{|c|}{$\begin{array}{c}\text { Kelompok } \\
\text { kontrol }(n=20)\end{array}$} & \multirow[t]{2}{*}{$\begin{array}{c}P- \\
\text { value }\end{array}$} \\
\hline & & Jumlah & $\%$ & Jumlah & $\%$ & \\
\hline \multirow[t]{2}{*}{ Jenis kelamin } & Laki - laki & 13 & 65 & 9 & 45 & $0,375^{\mathrm{a}}$ \\
\hline & Perempuan & 7 & 35 & 10 & 55 & \\
\hline \multirow[t]{3}{*}{ Usia (tahun) } & $<49$ & 5 & 25 & 4 & 25 & $0,625^{a}$ \\
\hline & $50-59$ & 4 & 20 & 5 & 20 & \\
\hline & $\geq 60$ & 11 & 55 & 11 & 55 & \\
\hline \multirow[t]{3}{*}{ Pendidikan } & Tidak sekolah/SD & 5 & 25 & 7 & 35 & $0,126^{a}$ \\
\hline & SMP/SMA & 14 & 70 & 13 & 65 & \\
\hline & Perguruan tinggi & 1 & 5 & - & - & \\
\hline \multirow[t]{2}{*}{ Pekerjaan } & Bekerja & 13 & 65 & & 60 & $1,000^{a}$ \\
\hline & Tidak bekerja & 7 & 35 & 8 & 40 & \\
\hline \multirow[t]{3}{*}{ Penghasilan } & $<1$ juta & 9 & 45 & 9 & 45 & $0.973^{\mathrm{a}}$ \\
\hline & $\geq 1-5$ juta & 7 & 34 & 9 & 45 & \\
\hline & $>5$ juta & 4 & 20 & 2 & 10 & \\
\hline \multirow[t]{2}{*}{ Status } & Menikah & 15 & 75 & 14 & 70 & $0,613^{\mathrm{a}}$ \\
\hline & Tidak menikah & 5 & 25 & 6 & 30 & \\
\hline \multirow[t]{3}{*}{ BMI } & Underweight & 3 & 15 & 15 & 75 & $0,590^{\mathrm{a}}$ \\
\hline & Normal & 9 & 45 & 5 & 25 & \\
\hline & Overweight & 8 & 40 & - & - & \\
\hline \multirow[t]{3}{*}{ Olahraga } & Tidak olahraga & 12 & 60 & 13 & 65 & $0,356^{\mathrm{a}}$ \\
\hline & Kadang-kadang & 8 & 40 & 6 & 30 & \\
\hline & Rutin & - & - & 1 & 5 & \\
\hline \multirow[t]{3}{*}{ Lama sakit } & $<1$ tahun & 2 & 10 & 2 & 10 & $0,940^{\mathrm{a}}$ \\
\hline & $1-5$ tahun & 15 & 75 & 17 & 85 & \\
\hline & $>5$ tahun & 3 & 15 & 1 & 5 & \\
\hline Derajat hipertensi & Stage 1 & 12 & 60 & 13 & 65 & $1,000^{\mathrm{a}}$ \\
\hline
\end{tabular}




\begin{tabular}{cccccc}
\hline Variabel & \multicolumn{2}{c}{ Kelompok } & \multicolumn{2}{c}{ Kelompok } & $\begin{array}{c}P \text { - } \\
\text { kalue }\end{array}$ \\
\cline { 2 - 5 } & intervensi (n=20) & kontrol (n=20) & vamlah & \% \\
\hline Stage 2 & 8 & 40 & 7 & 35 \\
\hline
\end{tabular}

${ }^{a}$ Uji statistik chi- square

Pemberian PIO menggunakan media leaflet disertai MRC diharapkan dapat memperbaiki kepatuhan pasien dalam minum obat hipertensi. Terdapat peningkatan persentase kepatuhan pada kelompok intervensi yaitu pada kategori kepatuhan tinggi yang awalnya 5\% menjadi 30\%, kepatuhan sedang dari $25 \%$ menjadi 70 \% dan tidak terdapat pasien dengan kepatuhan rendah setelah intervensi. Berbeda dengan kelompok kontrol dimana tidak terdapat kepatuhan tinggi pada akhir penelitian. Perubahan hanya sedikit terjadi pada kepatuhan sedang dari awal penelitian sebanyak 50\% menjadi 55\% (Tabel 2).

Tabel 2. Tingkat kepatuhan minum obat pada kelompok intervensi dan kelompok kontrol

\begin{tabular}{|c|c|c|c|c|c|}
\hline \multirow{2}{*}{\multicolumn{2}{|c|}{ Kepatuhan }} & \multicolumn{2}{|c|}{$\begin{array}{l}\text { Kelompok intervensi } \\
(n=20)\end{array}$} & \multicolumn{2}{|c|}{$\begin{array}{c}\text { Kelompok kontrol } \\
(\mathrm{n}=20)\end{array}$} \\
\hline & & Jumlah & $\%$ & Jumlah & $\%$ \\
\hline \multirow{3}{*}{$\begin{array}{l}\text { Sebelum } \\
\text { intervensi }\end{array}$} & Tinggi & 1 & 5 & - & - \\
\hline & Sedang & 5 & 25 & 10 & 50 \\
\hline & Rendah & 14 & 70 & 10 & 50 \\
\hline & Tinggi & 6 & 30 & - & - \\
\hline \multirow{2}{*}{ intervensi } & Sedang & 14 & 70 & 11 & 55 \\
\hline & Rendah & - & - & 9 & 45 \\
\hline
\end{tabular}

Tabel 3. Perbedaan kepatuhan minum obat pada kelompok intervensi

\begin{tabular}{cccc}
\hline & Rata-rata & Selisih & p value \\
\hline Sebelum intervensi & 1,05 & \multirow{2}{*}{2,050} & $0,000^{\mathrm{b}}$ \\
\hline Sesudah intervensi & 3,10 & &
\end{tabular}

Hasil analisis dengan uji-t berpasangan memperlihatkan perbedaan yang signifikan $(\mathrm{p}<0,001$ $(\mathrm{p}<0,050)$ ) pada kepatuhan minum obat sebelum dan sesudah intervensi, seperti yang tercantum dalam Tabel 3. Kepatuhan minum obat pada awal dan akhir penelitian diketahui tidak mengalami perubahan secara signifikan $(\mathrm{p}=0,271(\mathrm{p}<0,050)$ ). Selanjutnya, hasil uji wilcoxon menunjukkan kepatuhan minum obat pada minggu ke-empat antara kelompok intervensi dan kontrol berbeda secara signifikan $(\mathrm{p}<0,001)$. Dengan demikian, dapat disimpulkan bahwa perubahan tingkat kepatuhan pada kelompok intervensi benar-benar dipengaruhi oleh intervensi yang diberikan berupa PIO menggunakan media leaflet dan pemberian MRC.

Selain diharapkan berpengaruh terhadap kepatuhan pasien dalam minum obat, PIO dengan media leaflet dan MRC juga diharapkan akan berpengaruh terhadap outcome klinis, yaitu dapat menurunkan tekanan darah pasien. Uji mann-whitney digunakan untuk menganalisis penurunan tekanan darah sistolik dan diastolik saat sebelum dan setelah intervensi (Tabel 4). 
Pada Tabel 4 menunjukkan tidak ada perbedaan tekanan darah sistolik ( $p=0,396(p>0,050)$ ) dan tekanan darah diastolik $(p=0,564(p>0,050)$ ) sebelum dan sesudah intervensi. Penelitian terdahulu menyebutkan bahwa pill box dapat memperbaiki kepatuhan $(\mathrm{p}<0,001)$ dan menurunkan tekanan darah sistolik dan diastolik secara signifikan $(\mathrm{p}<0,001$ dan $\mathrm{p}=0,002)$, sedangkan penggunaan MRC hanya berpengaruh terhadap kepatuhan ( $\mathrm{p}<0,001)$ (Sammulia et al., 2016). Kombinasi PIO menggunakan media leaflet dengan MRC belum terbukti dapat menurunkan tekanan darah. Penelitian terdahulu melaporkan hasil yang berbeda, yaitu pemberian PIO pada pasien PROLANIS efektif dalam meningkatkan kepatuhan $(\mathrm{p}=0,002)$ dan menurunkan tekanan darah diastolik dan sistolik pada pasien hipertensi (Idacahyati, 2018). Perbedaan ini dapat terjadi karena subjek penelitian yang berbeda atau bentuk PIO yang diberikan juga berbeda. Faktor yang berhubungan dengan kepatuhan penggunaan obat di fasilitas pelayanan kesehatan meliputi durasi terapi $(\mathrm{p}=0,017)$, usia $(\mathrm{p}=021)$, pendidikan $(\mathrm{p}=0,034)$, dan komorbid $(\mathrm{p}=0,036)$ dengan nilai odds ratio durasi terapi $(\mathrm{OR}=0,26)$, usia $(\mathrm{OR}=5,43)$, pendidikan $(\mathrm{OR}=2,14)$ dan komorbid $(\mathrm{OR}=6,00)$. Berdasarkan nilai odd ratio tersebut diketahui bahwa kepatuhan dalam pengobatan hipertensi dipengaruhi oleh kondisi komorbid, usia, dan pendidikan (Rikmasari et al., 2020). Penelitian lainnya membuktikan bahwa peningkatan kepatuhan minum obat $(\mathrm{p}<0,05)$ dan penurunan tekanan darah sistolik $(\mathrm{p}<0,05)$ dapat dilakukan dengan pemberian pill card (Setiani et al., 2021). Hal tersebut berbeda dengan penelitian ini yang belum dapat membuktikan pengaruh PIO dan MRC terhadap pencapaian outcome terapi.

Tabel 4. Hasil Uji perbedaan penurunan tekanan darah sebelum dan setelah intervensi

\begin{tabular}{|c|c|c|c|c|c|c|c|}
\hline & & & \multicolumn{2}{|c|}{$\begin{array}{c}\text { Kelompok intervensi } \\
(n=20)\end{array}$} & \multicolumn{2}{|c|}{$\begin{array}{c}\text { Kelompok kontrol } \\
(n=20)\end{array}$} & \multirow[t]{2}{*}{ p value } \\
\hline & & & Mean \pm SD & Min - max & Mean \pm SD & Min - max & \\
\hline $\begin{array}{l}\text { Tekanan } \\
\text { (mm/Hg) }\end{array}$ & darah & sistolik & $9,00 \pm 9,119$ & $-10-20$ & $7,00 \pm 5,712$ & $0-20$ & $0,396^{c}$ \\
\hline $\begin{array}{l}\text { Tekanan } \\
\text { (mm/Hg) }\end{array}$ & darah & siastolik & $2,00 \pm 5,231$ & $-10-10$ & $3,00 \pm 4,702$ & $0-10$ & $0,564^{c}$ \\
\hline
\end{tabular}

Penurunan tekanan darah diharapkan mencapai target terapi untuk mencegah kejadian penyakit kardiovaskular, serebrovaskular dan gagal ginjal. Menurut JNC VIII, tekanan darah ditargetkan pada pasien usia < 60 tahun yaitu $<140 / 90 \mathrm{mmHg}$ dan usia $\geq 60$ tahun yaitu $<150 / 90$ mmHg serta pada pasien dengan diabetes mellitus dan pasien dengan CKD yaitu < 140/90 mmHg (James et al., 2014). Intervensi yang dilakukan pada penelitian ini belum dapat menurunkan tekanan darah, dengan faktor penyebab yang mungkin yaitu intervensi hanya dilakukan satu kali dengan periode waktu 4 minggu, sehingga selanjutnya perlu dilakukan penelitian dengan frekuensi yang lebih sering dan jangka waktu penilaian yang lebih lama. 
Kepatuhan bukan satu - satunya faktor yang mempengaruhi terkontrolnya tekanan darah. Faktor yang telah diidentifikasi menjadi penyebab kegagalan untuk menormalkan tekanan darah, yaitu tidak mempunyai asuransi kesehatan, kurangnya akses ke layanan kesehatan, tidak adanya tempat pelayanan kesehatan untuk kontrol rutin, kegagalan untuk diagnosis hipertensi (kegagalan untuk menilai tekanan darah tinggi yang tidak menampakkan gejala, pengukuran tekanan darah tidak akurat, gagal mengenali penyakit hipertensi). Selain itu juga dapat disebabkan oleh inersia terapi dari klinisi, inadekuat edukasi pasien, tidak adanya pengambilan keputusan bersama, rekomendasi gaya hidup dan konseling inadekuat, kepatuhan rendah terhadap modifikasi gaya hidup dan atau kepatuhan terhadap obat antihipertensi yang diresepkan, tidak ada pemantauan dan pelaporan tekanan darah dari rumah, rendahnya kesadaran pasien dan/atau penyedia pelayanan kesehatan akan target tekanan darah serta tidak adanya follow up yang sistematik. Untuk mengatasi tekanan darah tidak terkontrol diperlukan suatu intervensi dengan strategi berbasis populasi yang sesuai dengan fokus memastikan pasien memiliki tempat perawatan kesehatan untuk pemeriksaan rutin, mengoptimalkan kepatuhan, dan meminimalkan inersia terapi yang terkait dengan kontrol tekanan darah tinggi (Carey et al., 2018).

Intervensi untuk meningkatkan kepatuhan pengobatan pada pasien hipertensi dapat dilakukan di tingkat dokter, pasien, terapi obat, dan sistem perawatan kesehatan (Burnier \& Egan, 2019). Beberapa hal yang dapat dilakukan antara lain kolaborasi dokter dengan perawat dan apoteker, manajemen diri dengan sistem yang sederhana, penggunaan pengingat, adanya sesi kelompok, instruksi yang dikombinasikan dengan strategi motivasi, dukungan sistem kesehatan terhadap pemantauan dan secara finansial mendukung kolaborasi antara penyedia layanan kesehatan (perawat dan apoteker) (Williams et al., 2018). Intervensi apoteker berkolaborasi dengan dokter dalam banyak penelitian dilaporkan dapat meningkatkan kontrol tekanan darah dan hemat biaya (Rikmasari et al., 2021).

Keterbatasan dalam penelitian ini yaitu terdapat kemungkinan bias hasil mengingat subjek penelitian mengetahui sedang ikut serta dalam penelitian. Selain itu, data tekanan darah diperoleh berdasarkan data yang tercatat pada rekam medik, sehingga peneliti tidak dapat memastikan prosedur pengukuran tekanan darah telah dilakukan sesuai prosedur dan sama pada semua subjek penelitian. Aktivitas PIO menggunakan media leaflet serta MRC berpotensi untuk memperbaiki kepatuhan minum obat, namun belum terbukti dapat menurunkan tekanan darah. Penelitian serupa dengan memodifikasi bentuk pelatihan tenaga farmasi, bentuk PIO, media yang digunakan dan frekuensi intervensi dapat dilakukan. Selain itu dapat dirancang bentuk intervensi lain yang disesuaikan dengan kondisi masyarakat di setiap daerah dengan memperhatikan faktor - faktor yang 
mempengaruhi kepatuhan dan pengendalian tekanan darah. Pelayanan kefarmasian di fasilitas pelayanan kesehatan primer dapat berdampak positif terhadap kepatuhan pasien hipertensi dalam minum obat.

\section{Kesimpulan}

Berdasarkan hasil penelitian di atas dapat disimpulkan bahwa terdapat perbedaan antara kepatuhan minum obat sebelum dan setelah mendapatkan intervensi $(\mathrm{p}<0,001)$. Selain itu juga ada perbedaan $(\mathrm{p}<0,001)$ tingkat kepatuhan minum obat antara kelompok kontrol dengan intervensi serta tidak ada perbedaan tekanan darah sistolik dan diastolik sebelum dan sesudah intervensi ( $p>0,050$ ). Pada penelitian ini disimpulkan PIO menggunakan media leaflet dan pemberian MRC pada pasien hipertensi di fasilitas pelayanan kesehatan primer berpengaruh terhadap tingkat kepatuhan minum obat namun tidak memberikan pengaruh terhadap penurunan tekanan darah sistolik dan diastolik.

\section{Ucapan terimakasih}

Terimakasih kepada Puskesmas Abab yang telah memberikan kesempatan melakukan penelitian.

\section{Daftar pustaka}

Badan_Penelitian_dan_Pengembangan_Kesehatan. (2019). Riskesdas 2018: Laporan Provinsi Sumatera Selatan. Palembang: Badan Penelitian dan Pengembangan Kesehatan

Burnier, M., \& Egan, B. M. (2019). Adherence in Hypertension. Circ Res, 124(7), 1124-1140. doi:10.1161/circresaha.118.313220

Carey, R. M., Muntner, P., Bosworth, H. B., \& Whelton, P. K. (2018). Prevention and Control of Hypertension: JACC Health Promotion Series. J Am Coll Cardiol, 72(11), 1278-1293. doi:10.1016/j.jacc.2018.07.008

Dipiro, J. T., Talbert, R. L., Yee, G. C., Matzke, G. R., Wells, B. G. L., \& Posey, M. (2017). Pharmacotherapy A Pathophysiologic Approach (10 ed.). New York: Mc Graw Hill Education.

Ho, P. M., Bryson, C. L., \& Rumsfeld, J. S. (2009). Medication Adherence: Its Importance in $\begin{array}{llll}\text { Cardiovascular } \quad \text { Outcomes. } & \text { 3028-3035. }\end{array}$ doi:10.1161/circulationaha.108.768986

Idacahyati, K. (2018). Peningkatan Kepatuhan Pasien Hipertensi Dengan Pemberian Informasi Obat. Jurnal Kesehatan Bakti Tunas Husada: Jurnal Ilmu-ilmu Keperawatan, Analis Kesehatan dan Farmasi, 17(2), 243. doi:10.36465/jkbth.v17i2.228

James, P. A., Oparil, S., Carter, B. L., Cushman, W. C., Dennison-Himmelfarb, C., Handler, J., Lackland, D. T., LeFevre, M. L., MacKenzie, T. D., Ogedegbe, O., Smith, S. C., Jr., Svetkey, L. P., Taler, S. J., Townsend, R. R., Wright, J. T., Jr., Narva, A. S., \& Ortiz, E. (2014). 2014 Evidence-Based Guideline for The Management of High Blood Pressure In Adults: Report from The Panel Members Appointed to The Eighth Joint National Committee (JNC 8). Jama, 311(5), 507-520. doi:10.1001/jama.2013.284427 
Kemenkes. (2019a). Hipertensi Si Pembunuh Senyap Retrieved from https://pusdatin.kemkes.go.id/resources/download/pusdatin/infodatin/infodatinhipertensi-si-pembunuh-senyap.pdf

Kemenkes. (2019b). Laporan Nasional Riset Kesehatan Dasar. Jakarta: Kementerian Kesehatan RI

Kemenkes. (2019c). Pedoman Pelayanan Kefarmasian pada Hipertensi. Jakarta: Kementerian Kesehatan RI Retrieved from 10.1017/CB09781107415324.004

Omboni, S., \& Caserini, M. (2018). Effectiveness of Pharmacist's Intervention in The Management of Cardiovascular Diseases. Open Heart, 5(1), e000687. doi:10.1136/openhrt-2017-000687

Rikmasari, Y., Kristina, S. A., Andayani, T. M., \& Endarti, D. (2021). An Economic Evaluation of Pharmacist Intervention to Improve Blood Pressure Control: A Systematic Review International Journal of Pharmaceutical Research, 13(2), 1320-1332.

Rikmasari, Y., Rendowati, A., \& Putri, A. (2020). Faktor-faktor yang Mempengaruhi Kepatuhan Menggunakan Obat Antihipertensi: Cross Sectional Study di Puskesmas Sosial Palembang. Jurnal Penelitian Sains, 22(2), 87-94.

Sammulia, S. F., Rahmawati, F., \& Andayani, T. M. (2016). Perbandingan Pill Box dan Medication Chart dalam Meningkatkan Kepatuhan dan Outcome Klinik Geriatri Kota Batam. Jurnal Manajemen dan Pelayanan FarmasI (Journal of Management and Pharmacy Practice), 6(4), 288-296. doi:10.22146/jmpf.358

Setiani, L. A., Nurdin, N. M., \& Rakasiwi, I. A. (2021). Pengaruh Pemberian Pill Card terhadap Kepatuhan Minum Obat dan Tekanan Darah Pasien Hipertensi di RS PMI Kota Bogor. Fitofarmaka, 11(1), 51-66.

Still, C. H., Margevicius, S., Harwell, C., Huang, M. C., Martin, L., Dang, P. B., \& Wright Jnr, J. T. (2020). A Community and Technology-Based Approach for Hypertension Self-Management (COACHMAN) to Improve Blood Pressure Control in African Americans: Results from a Pilot Study. Patient Prefer Adherence, 14, 2301-2313. doi:10.2147/ppa.S283086

Sugiyono. (2019). Metode Penelitian Kuantitatif (Setiyawarni Ed.). Bandung: Alfabeta.

WHO. (2003). Adherence to Long-Term Therapies: Evidence for Action. Retrieved from doi: $10.1177 / 1049909112449068$

Williams, B., Mancia, G., Spiering, W., Agabiti Rosei, E., Azizi, M., Burnier, M., Clement, D., Coca, A., De Simone, G., Dominiczak, A., Kahan, T., Mahfoud, F., Redon, J., Ruilope, L., Zanchetti, A., Kerins, M., Kjeldsen, S., Kreutz, R., Laurent, S., Lip, G. Y. H., McManus, R., Narkiewicz, K., Ruschitzka, F., Schmieder, R., Shlyakhto, E., Tsioufis, K., Aboyans, V., \& Desormais, I. (2018). 2018 Practice Guidelines for The Management of Arterial Hypertension of Tthe European Society of Hypertension and the European Society of Cardiology: ESH/ESC Task Force for the Management of Arterial Hypertension. J Hypertens, 36(12), 2284-2309. doi:10.1097/hjh.0000000000001961 